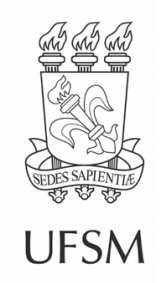

\title{
Artigos
}

\section{Análise da fauna edáfica em diferentes usos do solo no Bioma Pampa}

\author{
Analysis of the edaphic fauna in different soil uses in the Pampa Biome
}

\author{
Querina Ramos de Góes ${ }^{\bullet}$, Letiéri da Rosa Freitas "๑, \\ Leandro Homrich Lorentz III $\odot$, \\ Frederico Costa Beber Vieira III ๑, Mirla Andrade Weber III $\odot$ \\ ' Pesquisadora Autônoma, São Gabriel, RS, Brasil \\ " Pesquisadora Autônoma, Rio Pardo, RS, Brasil \\ I"' Universidade Federal do Pampa, São Gabriel, RS, Brasil
}

\section{RESUMO}

O solo é habitado por milhares de organismos responsáveis por diversas funções no ecossistema. Entre esses organismos, destacam-se os pertencentes à fauna do solo, a qual apresenta uma grande sensibilidade às modificações realizadas no meio, podendo ser considerada como um bom bioindicador de qualidade do solo. Assim, este trabalho teve como objetivo caracterizar a distribuição da fauna edáfica em diferentes usos do solo e em diferentes épocas do ano no município de São Gabriel - RS, avaliando a sua utilização como bioindicador da qualidade do solo. Foram realizadas avaliações da fauna do solo em três áreas de diferentes usos do solo: Mata Nativa, Campo Nativo Pastejado e Lavoura Azevém/Soja, em duas épocas distintas (inverno e verão). Durante as coletas, também foram avaliadas a temperatura, a umidade e a biomassa/serapilheira acumulada no solo, para verificar a influência que esses atributos exercem sobre a fauna do solo. Foram verificadas a abundância e a diversidade em nível de ordem dos indivíduos, sendo calculados os índices de diversidade, uniformidade e similaridade das áreas. Os resultados apresentaram uma grande diversidade de organismos edáficos, sendo Collembola, Hymenoptera e Acarina, os grupos com maior abundância no total das avaliações realizadas. Alguns grupos mostraram ser sensíveis a mudanças das variáveis ambientais. A área com maior diversidade e maior uniformidade foi a Mata Nativa, enquanto a Lavoura Azevém/Soja foi a menos diversa e menos uniforme. As áreas mais similares foram a Mata Nativa e o Campo Nativo Pastejado, durante as avaliações de inverno. Em termos gerais, a fauna edáfica apresenta potencial de ser utilizada na avaliação da qualidade do solo.

Palavras-chave: Método Provid; Biodiversidade do solo; Qualidade do solo 


\section{ABSTRACT}

The soil is populated by thousands of organisms which are responsible for various ecosystem functions. Among these organisms, those belonging to the soil fauna stand out and present a great sensitivity, responding to modifications in the environment, and may be regarded as a good soil quality bioindicator. This work aimed to characterize the edaphic fauna distribution in different soil uses and at different seasons of the year in São Gabriel, RS state, evaluating its use as a bio-indicator of the soil quality. Soil fauna evaluations were conducted in three areas of different soil uses: native forest, native pasture and ryegrass/soybean, in two distinct seasons (winter and summer). During the samples, the soil temperature, the soil water content and the biomass/litter were also evaluated, to verify the influence that these attributes exert on the soil fauna. The abundance and diversity were evaluated as well as the diversity, uniformity and similarity indexes in the areas were calculated. The results presented a large diversity of edaphic organisms. Collembola, Hymenoptera and Acarina were the groups with greater abundance. Some groups have shown to be sensitive to changes in environmental variables. The area with greater diversity and greater uniformity was the native forest, while the ryegrass/soybean had the least diversity and uniformity. The most similar areas were the native forest and the native pasture in the winter evaluations. The soil fauna presents potential to be used as a soil quality bioindicator.

Keywords: Provid method; Soil biodiversity; Soil quality

\section{INTRODUÇÃO}

O solo é considerado um sistema vivo, não apenas por ser habitat de uma gigantesca e diversa população de invertebrados, mas por esses organismos serem responsáveis por inúmeras funções dentro do solo, as quais são indispensáveis para o adequado funcionamento desse sistema (ANDERSON, 2009). Dentre esses processos pode-se destacar a fragmentação e incorporação de material orgânico ao solo, aumento no teor de matéria orgânica, com a melhoria da fertilidade e das propriedades físicas do solo, pelo favorecimento à agregação e pela construção de túneis e galerias, entre outros aspectos (MAAß; CARUSO; RILLIG, 2015).

A alteração do ambiente tem como uma de suas consequências a modificação nas características biológicas do solo, que podem ser afetadas de maneiras diferentes, a curto, médio e longo prazo. A alteração da cobertura vegetal e demais práticas do manejo agrícola perturbam a fauna e os microrganismos, não somente pelas mudanças nas propriedades do solo, mas também pela ação direta dessas práticas (GONGALSKY et al., 2016), influenciando tanto no número como nos grupos 
taxonômicos dos organismos edáficos presentes no ambiente. Sendo assim, a diversidade e a abundância da fauna do solo podem variar de acordo com o tipo de uso do solo. Portanto, locais com maior diversidade de espécies vegetais, que, por consequência, produzem serapilheira mais rica e heterogênea, favorecem um recurso alimentar de melhor qualidade e nichos mais diversificados para o desenvolvimento da fauna edáfica, resultando na ocorrência de um maior número de grupos funcionais e taxonômicos, e maior riqueza de espécies (MELO et al., 2009). Devido à relação direta com os processos do solo, a fauna edáfica tem sido apontada como um bom indicador da qualidade do mesmo (LAVELLE et al., 2006), sendo usada para comparar manejos e usos do solo (JEREZ-VALLE et al., 2014). Em comparação a outros indicadores de qualidade utilizados, como propriedades físicas e químicas, os organismos do solo possuem maior sensibilidade a modificações no meio (LIMA et al., 2007), respondendo com relativa rapidez (REICHERT; REINERT; BRAIDA, 2003).

Frente à perda da qualidade ambiental e da biodiversidade dos ecossistemas nativos, destaca-se a situação do bioma Pampa, o qual ocupa $176.496 \mathrm{~km}^{2}$ das terras brasileiras e constitui-se predominantemente de pastagens nativas, possuindo entre 3000 e 4000 espécies de plantas (ROESCH et al., 2009). Devido a suas características forrageiras, a atividade econômica principal no bioma Pampa é a produção pecuária, pois sustenta cerca de 18 milhões de animais, principalmente bovinos (CARVALHO; BATELLO, 2009). Ao longo da história, o bioma natural do Pampa tem sido destruído pelas conversões contínuas em terras cultiváveis, pastagens e plantações florestais de espécies exóticas. Essa redução de áreas de pastagem nativa pode levar a uma perda sensível de biodiversidade (ROESCH et al., 2009), não só de espécies vegetais, mas também animais. Nesse sentido, é importante compreender o impacto dos diferentes usos do solo nesse bioma objetivando encontrar atividades agropecuárias que promovam a preservação dessa biodiversidade e qualidade do solo.

Nesse contexto, o objetivo do presente trabalho foi caracterizar a distribuição dos grupos da fauna edáfica em diferentes usos do solo no Pampa gaúcho, avaliando sua utilização como bioindicador da qualidade do solo no bioma Pampa. 


\section{MATERIAL E MÉTODO}

O estudo foi desenvolvido no interior do município de São Gabriel - RS, em três áreas com diferentes usos do solo, localizadas no Bioma Pampa. O município se situa entre as coordenadas de latitude $30^{\circ} 27^{\prime} \mathrm{S}$ e longitude $54^{\circ} 19^{\prime} \mathrm{O}$, em uma altitude de 109 m na região fisiográfica da Campanha Gaúcha no Estado do Rio Grande do Sul. O clima é do tipo Cfa (clima temperado úmido com verão quente), conforme a classificação de Köppen (PESSOA, 2017). As áreas avaliadas foram de mata nativa, campo nativo pastejado e lavoura em sistema plantio direto com rotação soja no verão e azevém pastejado no inverno, em duas épocas do ano (Tabela 1). A localização das áreas encontra-se na Figura 1.

No dia 17 de setembro de 2016 (período de transição para a primavera), foram instaladas nas três áreas de estudo, com a utilização de um trado holandês, 45 armadilhas elaboradas a partir do método Provid (ANTONIOLLI et al., 2006). Essas armadilhas foram constituídas por garrafas de plástico tipo Pet com capacidade de dois litros, com quatro aberturas no formato de janelas com dimensões de $6 \times 4 \mathrm{~cm}$ na altura de $20 \mathrm{~cm}$ de sua base. Foram distribuídas 15 armadilhas em cada área, com espaçamento de $8 \mathrm{~m}$ entre elas, contendo em seu interior $200 \mathrm{ml}$ de uma solução de álcool $70 \%$ mais $1 \%$ de glicerina. No momento da instalação das armadilhas, foram coletadas amostras de solo em um raio de 1,0 $\mathrm{m}$ a partir da armadilha com auxílio de trado calador na camada de 0-10 cm para avaliação da umidade do solo.

Sete dias após a instalação, as armadilhas foram recolhidas e levadas ao Laboratório e Solos e Ecologia Florestal da Universidade Federal do Pampa, no qual os organismos coletados foram lavados em peneira de $53 \mu \mathrm{m}$, acondicionados em recipientes plásticos devidamente identificados contendo álcool 70\%, e refrigerados para sua conservação, sendo, posteriormente, contados e identificados em diferentes grupos taxonômicos, com o auxílio de um microscópio estereoscópico com ampliação de até $40 x$. 
Durante a coleta, foi avaliada a temperatura do solo próximo às armadilhas (raio de $30 \mathrm{~cm}$ ), na profundidade de $5 \mathrm{~cm}$, no período da manhã. Em um raio de $1 \mathrm{~m}$ ao redor de cada armadilha foram coletadas amostras de serapilheira acumulada e/ou biomassa vegetal sobre o solo, com o auxílio de um gabarito de madeira de $25 \mathrm{~cm} \times 25$ $\mathrm{cm}$. As amostras de serapilheira e de biomassa foram secas em estufa a $65^{\circ} \mathrm{C}$ durante uma semana e depois foram pesadas.

Tabela 1 - Caracterização das áreas utilizadas na amostragem da fauna edáfica. São Gabriel - RS

\begin{tabular}{|c|c|c|c|c|c|c|c|}
\hline \multirow[t]{2}{*}{ Área } & $\begin{array}{l}\text { Altitude } \\
\text { média }\end{array}$ & Área & $\begin{array}{l}\text { Carbono } \\
\text { orgânico }^{1}\end{array}$ & Areia $^{2}$ & Silte & Argila & \multirow[t]{2}{*}{ Características } \\
\hline & m & ha & & $\mathrm{g} \mathrm{kg}^{-1}$ & & & \\
\hline $\begin{array}{l}\text { Mata } \\
\text { Nativa }\end{array}$ & 69 & 35 & 54,99 & 410 & 479 & 111 & $\begin{array}{l}\text { Com introdução de bovinos } \\
\text { há pelo menos } 30 \text { anos } \\
\text { Com espécies vegetais como: } \\
\text { Matayba elaeagnoides Radlk e } \\
\text { Sorocea bonplandii (Baill.) W.C. } \\
\text { Burger, Lanjouw \& Boer }\end{array}$ \\
\hline $\begin{array}{l}\text { Campo } \\
\text { Nativo } \\
\text { Pastejado }\end{array}$ & 72 & 20 & 16,78 & 412 & 462 & 126 & $\begin{array}{l}\text { Lotação: } 1 \text { animal ha-1 } \\
\text { Altura da pastagem: } 10 \mathrm{~cm} \\
\text { Nesta condição, há pelo } \\
\text { menos } 30 \text { anos de pecuária } \\
\text { extensiva com bovinos. } \\
\text { Anteriormente, a área foi } \\
\text { cultivada com soja. }\end{array}$ \\
\hline $\begin{array}{l}\text { Lavoura } \\
\text { Azevém/ } \\
\text { Soja }\end{array}$ & 76 & 20 & - & $400^{3}$ & 450 & 150 & $\begin{array}{l}\text { Lavoura em plantio direto } \\
\text { com sucessão de culturas, } \\
\text { azevém pastejado no inverno } \\
\text { e soja no verão, há pelo } \\
\text { menos } 15 \text { anos. Práticas de } \\
\text { manejo seguem as Indicações } \\
\text { Técnicas para a Cultura da } \\
\text { Soja no RS. }\end{array}$ \\
\hline
\end{tabular}

Fonte: Autores (2017)

Legenda: ${ }^{1}$ Camada do solo avaliada: 0-10 cm, ${ }^{2}$ Camada do solo avaliada: 0-20 cm, ${ }^{3}$ Valores médios aproximados.

Entre os dias 23 e 30 de janeiro de 2017 foi feita a segunda coleta, repetindo os mesmos processos realizados na primeira. 
A abundância em cada área foi calculada pelo somatório da quantidade de indivíduos, enquanto a riqueza foi calculada pelo somatório do número de grupos taxonômicos encontrados.

Figura1 - Localização das áreas de realização do estudo (Mata Nativa: 304'46,322"O e 5356'32,914"S, Campo Nativo Pastejado: 304'38,971"O e 5356'33,379"S e Lavoura Azevém/ Soja: 305'1, 295"O e 5358'24,305"S). São Gabriel - RS

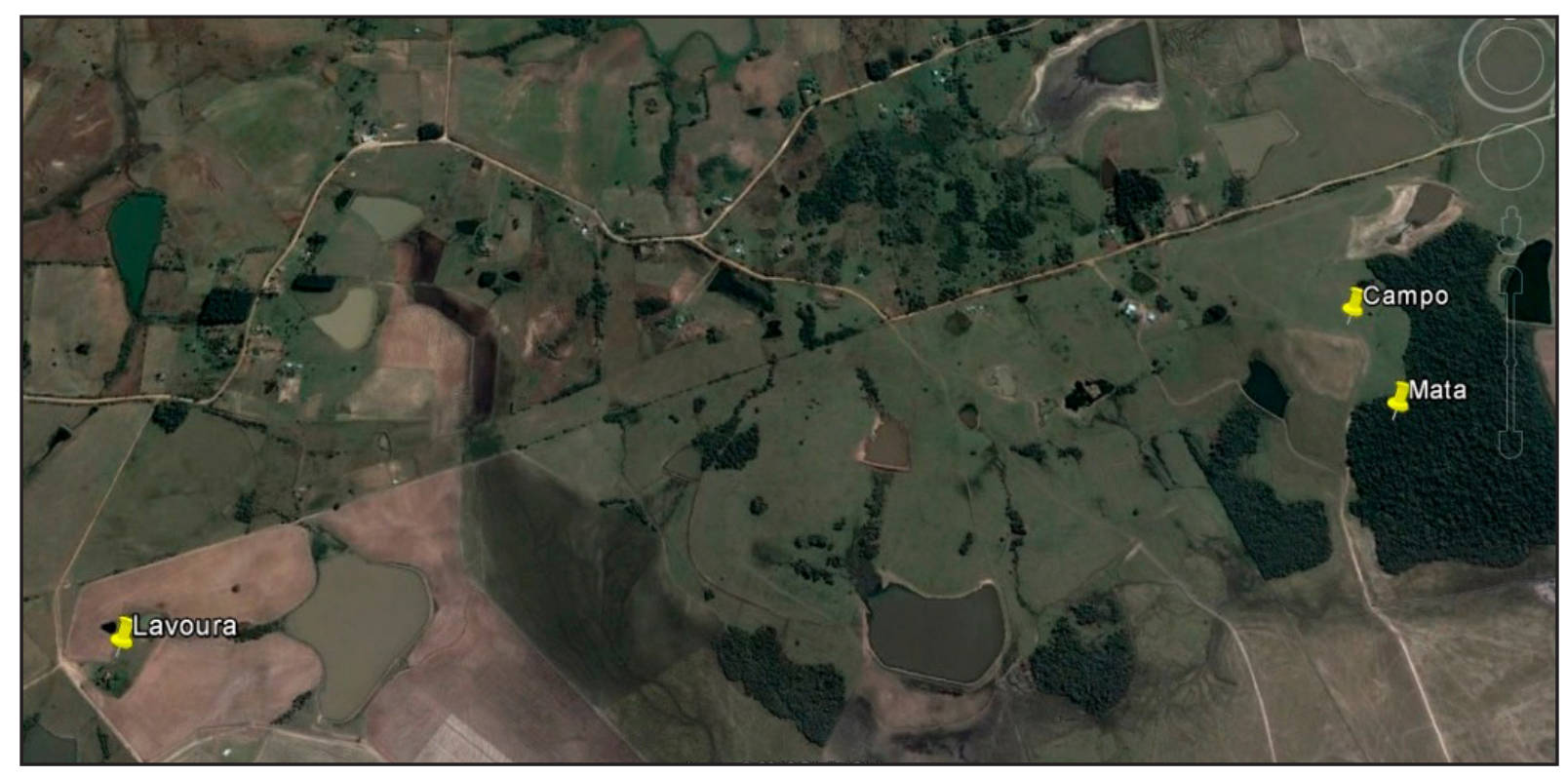

Fonte: Autores (2017)

A partir dos resultados obtidos, foram calculados os índices de diversidade de Shannon e de equitabilidade de Pielou de cada amostra e de cada área. Para analisar a semelhança entre as áreas, calculou-se o índice de similaridade de Jaccard.

O índice de diversidade de Shannon-Weaver foi calculado através da Equação (1):

$$
H^{\prime}=-\sum_{i=1}^{\mathrm{S}} p i \ln p i
$$

onde: $H^{\prime}$ é o índice de Shannon-Weaver; S é o número de grupos; $p i$ é a proporção do grupo $i$, estimada como ni/N, em que ni é a medida de importância do grupo $i$ (número de indivíduos); N é o número total de indivíduos (VILARDO et al., 2018). 
O cálculo do índice de equitabilidade de Pielou foi feito da seguinte maneira, Equação (2):

$\mathrm{J}=\frac{H^{\prime}}{\ln (S)}$

onde: J é o índice de equitabilidade de Pielou; $H$ ’ é o índice de Shannon-Weaver; $S$ é o número de grupos (VILARDO et al., 2018).

Para o cálculo do índice de similaridade de Jaccard, utilizou-se a Equação (3):

$\mathrm{Sj}=\frac{100 \cdot \mathrm{c}}{\mathrm{a}+\mathrm{b}+\mathrm{c}}$

onde: Sj é o índice de similaridade de Jaccard; a é o número de grupos que só ocorreram no local A; b é o número de grupos que só ocorreram no local B; c é o número de grupos encontrados em ambos os locais (JACCARD, 1908).

Aplicou-se a análise de correlação canônica entre os dois grupos de variáveis compostos por variáveis ambientais (temperatura, umidade e serapilheira ou biomassa) e a abundância de organismos em cada ordem ou grupo de indivíduos nas amostras para Campo Nativo Pastejado, Lavoura Azevém/Soja e Mata Nativa, considerando-se as duas épocas de coleta conjuntamente. Para essa análise foram desconsiderados os grupos com número de indivíduos menor que 40 no total de amostras e coletas, pois esses podem ser considerados raros em relação à quantidade de indivíduos dos demais grupos.

A correlação canônica foi processada pelo programa SAS (SAS INSTITUTE, 2008).

\section{RESULTADOS E DISCUSSÃO}

Durante o estudo da fauna edáfica, nas três áreas e nas duas coletas, foram encontrados no total 23 grupos taxonômicos, sendo eles: Acarina, Anura, Araneae, Blattodea, Chilopoda, Collembola, Coleoptera, Dermaptera, Diplopoda, Diptera, Embioptera, Gastropoda, Hemiptera, Hymenoptera, Homoptera, Isopoda, Lepidoptera, Neuroptera, Odonata, Oligochaeta, Opiliones, Orthoptera e Thysanoptera (Tabela 2). 
Foi encontrada maior abundância de indivíduos na análise realizada no inverno, nas três áreas avaliadas, porém o maior número de grupos foi encontrado no verão na área da Mata Nativa e na Lavoura Azevém/Soja (Tabela 2).

O grupo que mais se destacou, com maior frequência na maioria das áreas e épocas de coleta, foi a ordem Collembola, com exceção somente nas coletas na Mata Nativa e no Campo Nativo, realizados no verão (Tabela 2). Em vários estudos sobre fauna edáfica avaliando seu comportamento em diferentes usos do solo foi também observada uma frequência maior de colêmbolos na maioria das áreas analisadas no Brasil (BARETTA et al., 2006; SILVA et al., 2015). Entretanto, no presente estudo, os maiores números de organismos desse grupo foram registrados na área de lavoura, na qual representou $86 \%$ dos indivíduos coletados durante o inverno na cultura de azevém e $80 \%$ na coleta de verão em cultura de soja.

A simplificação do habitat na área de lavoura pelo monocultivo de azevém no inverno e de soja no verão influenciou a qualidade do alimento disponível à fauna edáfica, o que pode ter contribuído para a maior disponibilidade de alimento com características favoráveis aos colêmbolos e desfavorável a outros grupos, o que pode ter possibilitado o aumento da população de colêmbolos (CHAUVAT; ZAITSEF; WOLTERS, 2003). Sendo assim, a área cultivada com azevém, principalmente nas fases iniciais, pode ter contribuído para o aumento da quantidade de indivíduos do grupo dos colêmbolos, quando comparada aos demais usos do solo. Somado a isso, essa simplificação do habitat pode ter levado a uma diminuição drástica dos predadores de colêmbolos, possibilitando seu crescimento elevado (MORENTE; CAMPOS; RUANO, 2018). Em estudo realizado com diferentes sistemas de manejo, os tratamentos com revolvimento do solo e sem resíduos vegetais, ou seja, aqueles que mais simplificam o habitat, foram os que mais favoreceram as populações de colêmbolos, representando, em ambos os tratamentos, mais de $75 \%$ da ocorrência total (BARETTA et al., 2006).

O segundo grupo com maior quantidade de organismos encontrados foi Hymenoptera, sendo o grupo com maior abundância de indivíduos na Mata Nativa e no 
Campo Nativo Pastejado durante as coletas de verão (Tabela 2), com menor expressão na lavoura. Sistemas com maior disponibilidade de alimento e maior quantidade de material orgânico (no presente trabalho, a Mata Nativa e o Campo Nativo Pastejado) podem ter atraído maior número de decompositores que em sequência atraíram predadores, permitindo o estabelecimento de comunidades de formigas (CREPALDI et al., 2014). A alta abundância dessa ordem não deve estar relacionada apenas com prejuízos à produtividade agrícola, pois a maior parte dos grupos de formigas não é desfolhadora, e sim ser considerada de fundamental importância para a manutenção da qualidade do solo, sendo úteis como bioindicadores dessas condições (CREPALDI et al., 2014). Já outros autores sugerem que além do potencial de serem bioindicadores naturais das condições dos ecossistemas (SILVA et al., 2015) também são agentes controladores de pestes. Dessa forma, no presente estudo, a menor quantidade de formigas pode ser indicativo de uma menor qualidade ambiental na área de Lavoura Azevém/Soja, provavelmente devido à menor oferta de alimento pelo monocultivo associada à utilização de pesticidas.

O terceiro grupo com maior ocorrência de organismos foi Acarina, com maior destaque na área de Campo Nativo Pastejado no inverno, em que aparece em grande quantidade (Tabela 2). Conforme Sanginga, Mulongoy e Swift (1992), as atividades desenvolvidas pelos ácaros presentes no solo são de especial importância, pois resultam em melhorias nos atributos físicos do solo como porosidade, aeração, infiltração de água e no funcionamento biológico do solo. Portanto, a presença desses organismos em grande quantidade em área de Campo Nativo Pastejado é um aspecto positivo, já que contribui com a possibilidade de recuperação dos possíveis impactos causados pelo pastejo.

Outros grupos coletados em maior número de indivíduos foram das ordens Coleoptera e Diptera. Os primeiros foram coletados em maior quantidade na Mata Nativa na coleta de inverno. Já a ordem Díptera foi coletada em maior número nessa mesma área, porém na coleta realizada no verão (Tabela 2). Os coleópteros são 
organismos particularmente sensíveis ao preparo do solo, sendo reduzidos em áreas de cultivo (KLADIVKO, 2001).

O grupo Araneae também ocorreu em todas as áreas e épocas avaliadas. As aranhas são consideradas boas indicadoras no que se refere aos fatores físicos do ambiente como mudanças no microclima, portanto apresentam sensibilidade em áreas em que há qualquer tipo de intervenção antrópica, tendo sua população reduzida com a intensidade do uso do solo e efeitos degradantes (BARETTA, 2007). Esse fato pode explicar a menor ocorrência do grupo na lavoura com cultivo de soja (coleta de verão) (Tabela 2).

Em relação ao índice de diversidade de Shannon, os maiores valores foram encontrados na Mata Nativa, nas duas épocas de coleta. Os menores valores foram encontrados na área de lavoura, sendo por sua vez relacionados à predominância de organismos do grupo Collembola (Tabela 3), cujas possíveis causas foram discutidas anteriormente. Os valores para o índice de Shannon normalmente podem ter uma variação de 0 a 5 e a redução desse valor pode resultar da maior dominância de alguns grupos, em detrimento a outros (SOUTO et al., 2008). Segundo Souto et al. (2008), a diversidade de espécies está interligada a uma relação entre o número de espécies e a distribuição do número de indivíduos entre as espécies, ou seja, quanto maior o índice de Shannon, menor a variação da riqueza de espécie.

Em relação ao índice de equitabilidade de Pielou, o maior valor foi encontrado também na área de Mata Nativa durante a coleta de inverno (Tabela 3), como um indicativo da maior uniformidade na distribuição dos grupos de organismos edáficos nessa área, em relação aos demais. 0 índice de Pielou, que pode variar de 0 a 1, tem seus valores diretamente relacionados à dominância de grupos, ou seja, quanto menor o valor obtido, maior será a dominância por poucos grupos (PASQUALIN et al., 2012). Os menores valores foram encontrados na área de lavoura em ambas as épocas de coleta (Tabela 3). Esse resultado pode ser atribuído à predominância de indivíduos do grupo Collembola coletados nessa área. 
Tabela 2 - Abundância e diversidade de organismos dos grupos da fauna do solo coletados em áreas com diferentes usos do solo em dois períodos de coleta no município de São Gabriel - RS

\begin{tabular}{|c|c|c|c|c|c|c|c|c|c|}
\hline \multirow[b]{2}{*}{$\begin{array}{c}\text { Grupo } \\
\text { Taxonômico }\end{array}$} & \multicolumn{4}{|c|}{ Inverno } & \multicolumn{4}{|c|}{ Verão } & \multirow[b]{2}{*}{ TOTAL } \\
\hline & $\begin{array}{l}\text { Mata } \\
\text { Nativa }\end{array}$ & $\begin{array}{l}\text { Campo } \\
\text { Nativo }\end{array}$ & $\begin{array}{c}\text { Lavoura } \\
\text { Azevém } \\
\text { / Soja }\end{array}$ & $\begin{array}{c}\text { Total } \\
\text { da } \\
\text { Época }\end{array}$ & $\begin{array}{l}\text { Mata } \\
\text { Nativa }\end{array}$ & $\begin{array}{l}\text { Campo } \\
\text { Nativo }\end{array}$ & $\begin{array}{c}\text { Lavoura } \\
\text { Azevém } \\
\text { / Soja }\end{array}$ & $\begin{array}{c}\text { Total } \\
\text { da } \\
\text { Época }\end{array}$ & \\
\hline Acarina & 292 & 1240 & 789 & 2321 & 146 & 302 & 289 & 737 & 3058 \\
\hline Anura & 0 & 0 & 0 & 0 & 3 & 0 & 1 & 4 & 4 \\
\hline Araneae & 173 & 69 & 173 & 415 & 85 & 73 & 33 & 191 & 606 \\
\hline Blattodea & 0 & 0 & 0 & 0 & 1 & 3 & 8 & 12 & 12 \\
\hline Chilopoda & 0 & 0 & 0 & 0 & 1 & 0 & 0 & 1 & 1 \\
\hline Collembola & 773 & 2148 & 9008 & 11929 & 677 & 1031 & 3989 & 5697 & 17626 \\
\hline Coleoptera & 399 & 125 & 90 & 614 & 232 & 179 & 327 & 738 & 1352 \\
\hline Dermaptera & 0 & 0 & 0 & 0 & 1 & 0 & 2 & 3 & 3 \\
\hline Diplopoda & 0 & 3 & 11 & 14 & 0 & 0 & 5 & 5 & 19 \\
\hline Diptera & 199 & 112 & 101 & 412 & 260 & 75 & 30 & 365 & 777 \\
\hline Embioptera & 26 & 2 & 2 & 30 & 3 & 1 & 0 & 4 & 34 \\
\hline Gastropoda & 0 & 0 & 0 & 0 & 7 & 0 & 1 & 8 & 8 \\
\hline Hemiptera & 22 & 27 & 89 & 138 & 14 & 7 & 5 & 26 & 164 \\
\hline Hymenoptera & 527 & 993 & 139 & 1659 & 823 & 1405 & 123 & 2351 & 4010 \\
\hline Homoptera & 12 & 61 & 9 & 82 & 27 & 69 & 16 & 112 & 194 \\
\hline Isopoda & 3 & 7 & 0 & 10 & 0 & 2 & 0 & 2 & 12 \\
\hline Larvas & 11 & 5 & 4 & 20 & 22 & 5 & 24 & 51 & 71 \\
\hline Lepidoptera & 0 & 0 & 0 & 0 & 5 & 0 & 0 & 5 & 5 \\
\hline Neuroptera & 0 & 0 & 0 & 0 & 0 & 0 & 2 & 2 & 2 \\
\hline Odonata & 0 & 0 & 1 & 1 & 0 & 2 & 10 & 12 & 13 \\
\hline Oligochaeta & 0 & 0 & 2 & 2 & 2 & 0 & 0 & 2 & 4 \\
\hline Opiliones & 0 & 0 & 6 & 6 & 1 & 0 & 0 & 1 & 7 \\
\hline Orthoptera & 6 & 4 & 6 & 16 & 7 & 53 & 84 & 144 & 160 \\
\hline Thysanoptera & 28 & 44 & 0 & 72 & 18 & 44 & 46 & 108 & 180 \\
\hline TOTAL & 2471 & 4840 & 10430 & 17741 & 2335 & 3251 & 4995 & 10581 & 28322 \\
\hline
\end{tabular}

Fonte: Autores (2017)

O efeito da maior frequência de colêmbolos diminuindo os índices de Shannon e Pielou também foi observado por Cosseau et al. (2020) ao avaliarem a fauna epiedáfica como indicador de qualidade do solo em áreas contaminadas por chumbo. Neste estudo, as áreas que apresentaram elevada frequência de colêmbolos tiveram redução de uniformidade, assim como de diversidade, ocasionada pela dominância 
desse grupo em relação aos demais. Refletindo o resultado observado para o índice de Shannon, a área com menor teor desse metal apresentou maior índice de Pielou apesar da baixa abundância quando comparada a outras áreas. Esses resultados indicam que apenas a abundância total de organismos não é parâmetro capaz de refletir a qualidade do solo, visto que a área com maior abundância (Lavoura Azevém/Soja) apresentou menores índices de diversidade (Tabela 3). Os menores índices de Shannon e Pielou em áreas degradadas, cultivadas ou com manejos mais intensivos em comparação a áreas nativas ou com manejo mais conservacionista também foram observados nos estudos de Vilardo et al. (2018).

Tabela 3 - Número de indivíduos, número de grupos, índice de Shannon e índice de Pielou em áreas de diferentes usos do solo em dois períodos de coleta no município de São Gabriel - RS

\begin{tabular}{|c|c|c|c|c|c|c|}
\hline \multirow{2}{*}{ Áreas } & \multicolumn{2}{|c|}{$N^{\circ}$ de Grupos } & \multicolumn{2}{|c|}{ Shannon } & \multicolumn{2}{|c|}{ Pielou } \\
\hline & Inverno & Verão & Inverno & Verão & Inverno & Verão \\
\hline Mata Nativa & 12 & 19 & 1,82 & 1,71 & 0,73 & 0,58 \\
\hline Campo Nativo Pastejado & 13 & 14 & 1,43 & 1,52 & 0,56 & 0,58 \\
\hline Lavoura Azevém/Soja & 14 & 17 & 0,60 & 0,85 & 0,23 & 0,30 \\
\hline
\end{tabular}

Fonte: Autores (2017)

O cálculo do índice de similaridade de Jaccard demonstrou que as áreas em que ocorreram mais grupos em comum foram Mata Nativa e Campo Nativo Pastejado, nas análises realizadas no inverno, com 92\% de similaridade, sendo que as mesmas áreas no verão apresentaram o índice mais baixo (57\%). A comparação entre as áreas de Campo Nativo Pastejado e Lavoura Azevém/Soja resultou em 69\% de similaridade no inverno e 63\% no verão. As áreas de Mata Nativa e Lavoura Azevém/Soja apresentaram $62 \%$ de similaridade no inverno e $64 \%$ no verão (Tabela 4). A maior similaridade entre as áreas de Mata Nativa e Campo Nativo Pastejado pode ser atribuído ao fato desse grupo de áreas sofrerem menores impactos relacionados a intervenções antrópicas, em comparação aos outros grupos de áreas comparadas. 
Pode-se observar que para os índices calculados neste estudo, Shannon e Pielou, o Campo Nativo Pastejado apresentou valores bem superiores aos da Lavoura Azevém/ Soja e, embora menores, próximos aos da Mata Nativa, similaridade observada no alto índice de Jaccard calculado para o inverno. Isso demonstra que esse tipo de uso do solo na área do Pampa possivelmente contribui para a preservação da biodiversidade desse bioma.

Tabela 4 - Similaridade entre áreas de Mata Nativa, Campo Nativo Pastejado e Lavoura Azevém/Soja em diferentes épocas de coleta de fauna do solo no município de São Gabriel - RS

\begin{tabular}{lcc}
\hline \multirow{2}{*}{ Grupo de Áreas } & \multicolumn{2}{c}{ |sj' $^{\mathbf{1}}$} \\
\cline { 2 - 3 } & Inverno & Verão \\
\hline $\mathrm{M} \times \mathrm{C}$ & $92 \%$ & $57 \%$ \\
$\mathrm{C} \times \mathrm{L}$ & $69 \%$ & $63 \%$ \\
$\mathrm{M} \times \mathrm{L}$ & $62 \%$ & $64 \%$ \\
\hline
\end{tabular}

Fonte: Autores (2017)

Legenda: (M) Mata Nativa; (C) Campo Nativo; (L) Lavoura Azevém/Soja; ${ }^{1}$ Indice de similaridade de Jaccard.

Os resultados das avaliações dos atributos físicos (Tabela 5) das áreas estudadas demonstram que a Mata Nativa apresentou as temperaturas mais baixas em relação às outras áreas, tanto nas análises de inverno como nas de verão, sendo elas $14,7^{\circ} \mathrm{C}$ e $23,1^{\circ} \mathrm{C}$, respectivamente. As temperaturas mais altas foram encontradas na lavoura nas análises de inverno com $20,6^{\circ} \mathrm{C}$, e no campo nativo, nas análises realizadas no verão com $28,7^{\circ} \mathrm{C}$. Essas temperaturas mais baixas na Mata Nativa podem ser explicadas em razão do tipo de cobertura vegetal. A consequente maior temperatura na superfície do solo nessas áreas faz com que os organismos da fauna migrem para camadas mais internas do solo.

O solo com maior umidade foi o da Mata Nativa, com 0,41g g-1 no inverno e $0,36 \mathrm{~g} \mathrm{~g}^{-1}$ no verão. O Campo Nativo apresentou umidade do solo de $0,28 \mathrm{~g} \mathrm{~g}^{-1}$ no inverno e 0,22 $\mathrm{g} \mathrm{g}^{-1}$ no verão, enquanto na lavoura foram encontradas umidades mais 
baixas, variando de $0,26 \mathrm{~g} \mathrm{~g}^{-1}$ no inverno a $0,18 \mathrm{~g} \mathrm{~g}^{-1}$ no verão. As maiores umidades na Mata Nativa podem ser justificadas também pela maior cobertura do solo em relação às outras áreas, visto que no Campo Nativo e na lavoura, sendo as coberturas mais baixas e deficientes, o solo fica mais exposto à incidência de radiação solar, sendo mais fácil a perda de água por evaporação.

Tabela 5 - Médias das 15 avaliações dos atributos físicos do solo (temperatura, umidade) e serapilheira ou biomassa vegetal sobre o solo nas áreas de Mata Nativa, Campo Nativo Pastejado e Lavoura Azevém/Soja no município de São Gabriel - RS

\begin{tabular}{|c|c|c|c|c|c|c|}
\hline \multirow[t]{2}{*}{ Área } & \multicolumn{2}{|c|}{$\begin{array}{c}\text { Temperatura do solo }{ }^{1} \\
\left({ }^{\circ} \mathrm{C}\right)\end{array}$} & \multicolumn{2}{|c|}{$\begin{array}{c}\text { Umidade } \\
\text { gravimétrica }{ }^{2} \\
\left(\mathrm{~g} \mathrm{~g}^{-1}\right)\end{array}$} & \multicolumn{2}{|c|}{$\begin{array}{c}\text { Serapilheira/ } \\
\text { Biomassa aérea } \\
\left(\text { kg ha-1) }^{-1}\right.\end{array}$} \\
\hline & Inverno & Verão & Inverno & Verão & Inverno & Verão \\
\hline Mata Nativa & 14,69 & 23,11 & 0,41 & 0,36 & 9297 & 9897 \\
\hline $\begin{array}{l}\text { Campo Nativo } \\
\text { Pastejado }\end{array}$ & 20,60 & 28,73 & 0,28 & 0,22 & 5297 & 4316 \\
\hline Lavoura Azevém/Soja & 21,35 & 26,12 & 0,26 & 0,18 & 2686 & 2978 \\
\hline
\end{tabular}

Fonte: Autores (2017)

Legenda: 'Parâmetro avaliado a uma profundidade de $5 \mathrm{~cm}$; ${ }^{2}$ Média para a camada de 0-10 cm de profundidade.

As maiores quantidades de biomassa vegetal sobre o solo foram encontradas na Mata Nativa na forma de serapilheira, nas duas épocas de coleta, sendo elas 9297 kg ha-1 no inverno, e 9897 kg ha-1 no verão. A quantidade de biomassa no Campo Nativo variou de 5297 kg ha- ${ }^{-1}$ no inverno a 4316 kg ha-1 no verão. Na lavoura foram encontradas as quantidades de biomassa mais baixas, apresentando 2685 kg ha-1 no inverno e $2977 \mathrm{~kg} \mathrm{ha}^{-1}$ no verão. Através desses resultados, pode-se analisar a influência da qualidade e do tipo da cobertura vegetal na temperatura e na umidade, assim como na quantidade de alimento disponível no solo para os organismos da fauna edáfica. O fornecimento constante e heterogêneo de alta quantidade de material orgânico pela vegetação na Mata Nativa proporciona níveis mais adequados de temperatura e umidade e favorece as condições edáficas necessárias para abrigar 
uma maior diversidade (SILVA et al., 2006), ou seja, propicia condições mais favoráveis quanto à fonte de alimento e habitat para grande parte das espécies de invertebrados que habitam os solos, aumentando a disponibilidade de energia no sistema (AQUINO et al., 2008).

Através da análise de correlação canônica (Tabela 6) é possível observar que os coeficientes do primeiro par canônico para todas as condições de campo avaliadas foram significativos (p-valor inferior a 0,05), com valores de 0,86, 0,91 e 0,86 para Campo Nativo Pastejado, Lavoura Azevém/Soja e Mata Nativa, indicando que a presença ou abundância de algumas ordens são determinadas por variáveis ambientais preferenciais a essas.

Pode-se afirmar, portanto, que, no Campo Nativo, as condições de alta temperatura e baixa umidade favoreceram indivíduos da ordem Orthoptera, enquanto as condições opostas favoreceram os da ordem Acarina $(75,1 \%$ da variação total explicada). Comportamento semelhante foi encontrado em um estudo de Ducatti (2002), no qual se verificou maior densidade de ácaros em um solo com menor temperatura média e maior umidade. Na lavoura, observou-se que temperaturas mais elevadas favoreceram as ordens Homoptera e Orthoptera e enquanto desfavoreceram a Hymenoptera (80\% da variação total explicada). Na Mata Nativa, a quantidade de biomassa ganhou expressão, sendo que as condições de alta biomassa e baixa temperatura favoreceram as ordens Araneae, Coleoptera e Homoptera (57\% da variação total explicada), enquanto alta temperatura e alta biomassa indicaram maior presença de indivíduos da ordem Hymenoptera (37\% da variação total explicada).

Segundo Gonçalves et al. (2000), alguns fatores, como a redução das perdas de água por evaporação, assim como das amplitudes de variação térmica e hídrica do solo ao longo das estações climáticas do ano, fazem com que os organismos do solo encontrem um microambiente mais adequado para sua sobrevivência e multiplicação, ocorrendo em maior variedade e abundância.

Considerando todas as avaliações ambientais e biológicas realizadas e índices calculados pode-se observar a melhor qualidade ambiental da Mata Nativa, a qual 
apresentou melhores índices de Shannon e Pielou, o que vai ao encontro dos diversos estudos citados neste trabalho. Isto se deve à maior oferta de alimento e melhores condições de umidade e temperatura para a fauna edáfica nesse ambiente.

Tabela 6 - Correlação canônica dos três primeiros pares canônicos e sua significância, autovalores, proporção explicada por cada par e coeficientes canônicos e para abundância de indivíduos de diferentes ordens em diferentes condições de Campo Nativo Pastejado, Lavoura Azevém/Soja e Mata Nativa, considerando as duas estações conjuntamente

\begin{tabular}{|c|c|c|c|c|c|c|c|c|c|}
\hline \multirow[t]{3}{*}{ Estatísticas } & \multicolumn{9}{|c|}{ Locais de coleta } \\
\hline & \multicolumn{3}{|c|}{$\begin{array}{c}\text { Campo Nativo } \\
\text { Pastejado }\end{array}$} & \multicolumn{3}{|c|}{$\begin{array}{c}\text { Lavoura } \\
\text { Azevém/Soja }\end{array}$} & \multicolumn{3}{|c|}{$\begin{array}{l}\text { Mata } \\
\text { Nativa }\end{array}$} \\
\hline & $1^{\circ} \mathrm{Par}$ & $2^{\circ} \mathrm{Par}$ & $3^{\circ}$ Par & $1^{\circ} \mathrm{Par}$ & $2^{\circ} \mathrm{Par}$ & $3^{\circ}$ Par & $1^{\circ} \mathrm{Par}$ & $\begin{array}{c}2^{\circ} \\
\text { Par }\end{array}$ & $3^{\circ} \mathrm{Par}$ \\
\hline $\begin{array}{l}\text { Correlação } \\
\text { Canônica }\end{array}$ & 0,86 & 0,61 & 0,52 & 0,915 & 0,70 & 0,48 & 0,86 & 0,80 & 0,48 \\
\hline p-valor & 0,03 & 0,53 & 0,56 & 0,001 & 0,30 & 0,68 & $<0,003$ & 0,06 & 0,69 \\
\hline Autovalor & 2,90 & 0,60 & 0,37 & 5,135 & 0,99 & 0,30 & 2,77 & 1,80 & 0,29 \\
\hline $\begin{array}{l}\text { Proporção } \\
\text { explicada (\%) }\end{array}$ & 75,1 & 15,4 & 9,5 & 79,9 & 15,4 & 4,7 & 57,0 & 37,0 & 6,0 \\
\hline Descritor & & & oeficien & canônico & s para va & riáveis a & ientais & & \\
\hline Temperatura & 0,57 & 1,48 & 0,16 & $-1,06$ & 0,18 & 1,42 & $-0,70$ & 0,80 & $-0,28$ \\
\hline Umidade & $-0,58$ & 1,46 & $-0,04$ & $-0,07$ & 0,26 & 1,80 & 0,15 & 0,39 & $-1,06$ \\
\hline Biomassa & 0,27 & 0,002 & 1,06 & $-0,08$ & 1,06 & 0,34 & 0,68 & 0,48 & 0,69 \\
\hline Ordem & & Coeficie & es canô & s para al & undânci & a dos in & duos por & grupo & \\
\hline Acarina & $-0,49$ & 0,79 & 1,03 & 0,18 & 0,24 & 0,31 & 0,05 & 0,09 & 0,70 \\
\hline Araneae & $-0,15$ & 0,54 & 0,04 & 0,25 & $-0,09$ & 0,70 & 0,83 & 0,22 & $-1,16$ \\
\hline Collembola & $-0,23$ & $-0,75$ & $-0,94$ & 0,08 & 0,39 & $-0,85$ & $-0,32$ & $-0,20$ & 0,39 \\
\hline Coleoptera & 0,09 & 0,38 & $-0,65$ & $-0,16$ & 0,84 & $-0,13$ & 0,56 & $-0,18$ & 0,11 \\
\hline Diptera & 0,02 & $-0,05$ & 0,41 & 0,27 & 0,26 & 0,53 & $-0,17$ & 0,14 & 0,44 \\
\hline Hemiptera & 0,06 & $-0,78$ & $-0,06$ & 0,04 & $-0,11$ & $-0,64$ & 0,19 & 0,15 & $-0,005$ \\
\hline Hymenoptera & 0,16 & 0,21 & 0,51 & 0,34 & $-0,41$ & $-0,40$ & $-0,27$ & 0,89 & $-0,08$ \\
\hline Homoptera & 0,14 & $-0,19$ & $-0,55$ & $-0,33$ & $-0,41$ & 0,21 & 0,40 & 0,52 & 0,22 \\
\hline Orthoptera & 0,56 & $-0,40$ & 0,09 & $-0,30$ & 0,22 & 0,44 & $-0,26$ & 0,15 & $-0,27$ \\
\hline Thysanoptera & 0,26 & $-0,45$ & $-0,01$ & 0,06 & $-0,22$ & $-0,15$ & 0,00 & $-0,27$ & 0,58 \\
\hline
\end{tabular}

Fonte: Autores (2017) 
A representação gráfica da análise da correção canônica encontra-se na Figura 2.

Já a área Lavoura Azevém/Soja apresentou os piores índices. Nessa condição, o monocultivo de azevém no inverno e soja no verão proporcionou menor diversidade e oferta de alimento e condições de umidade e temperatura menos favoráveis à diversidade dos organismos edáficos.

Aárea de Campo Nativo Pastejado, embora com índices de diversidade um pouco inferiores aos da Mata Nativa, porém bem próximos, destacou-se como uso do solo na preservação da biodiversidade edáfica. Esse sistema de uso do solo no bioma Pampa apresenta-se como atividade agropecuária que pode proporcionar a preservação desse bioma. Entretanto, mais estudos com organismos do solo são necessários nessas áreas, objetivando encontrar sistemas de uso do solo que preservem o Pampa.

Figura 2 - Representação gráfica da análise de correlação canônica (CCA) entre os dois grupos de variáveis compostos por variáveis ambientais (temperatura, umidade e serapilheira ou biomassa) e a abundância de organismos em cada ordem ou grupo de indivíduos nas amostras para Campo Nativo Pastejado, Lavoura Azevém/Soja e Mata Nativa, considerando-se as duas épocas de coleta conjuntamente

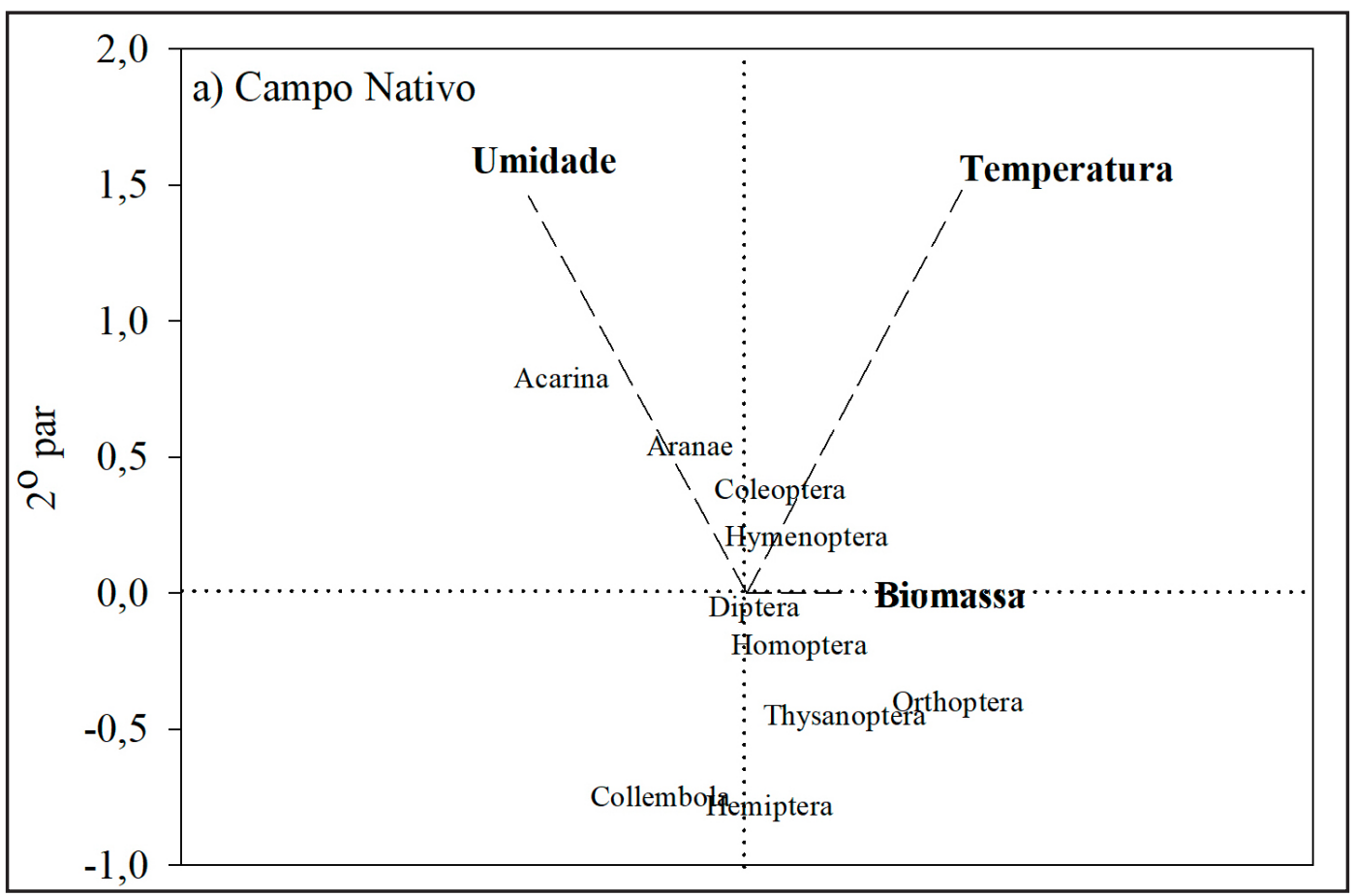


Figura 2 - Conclusão

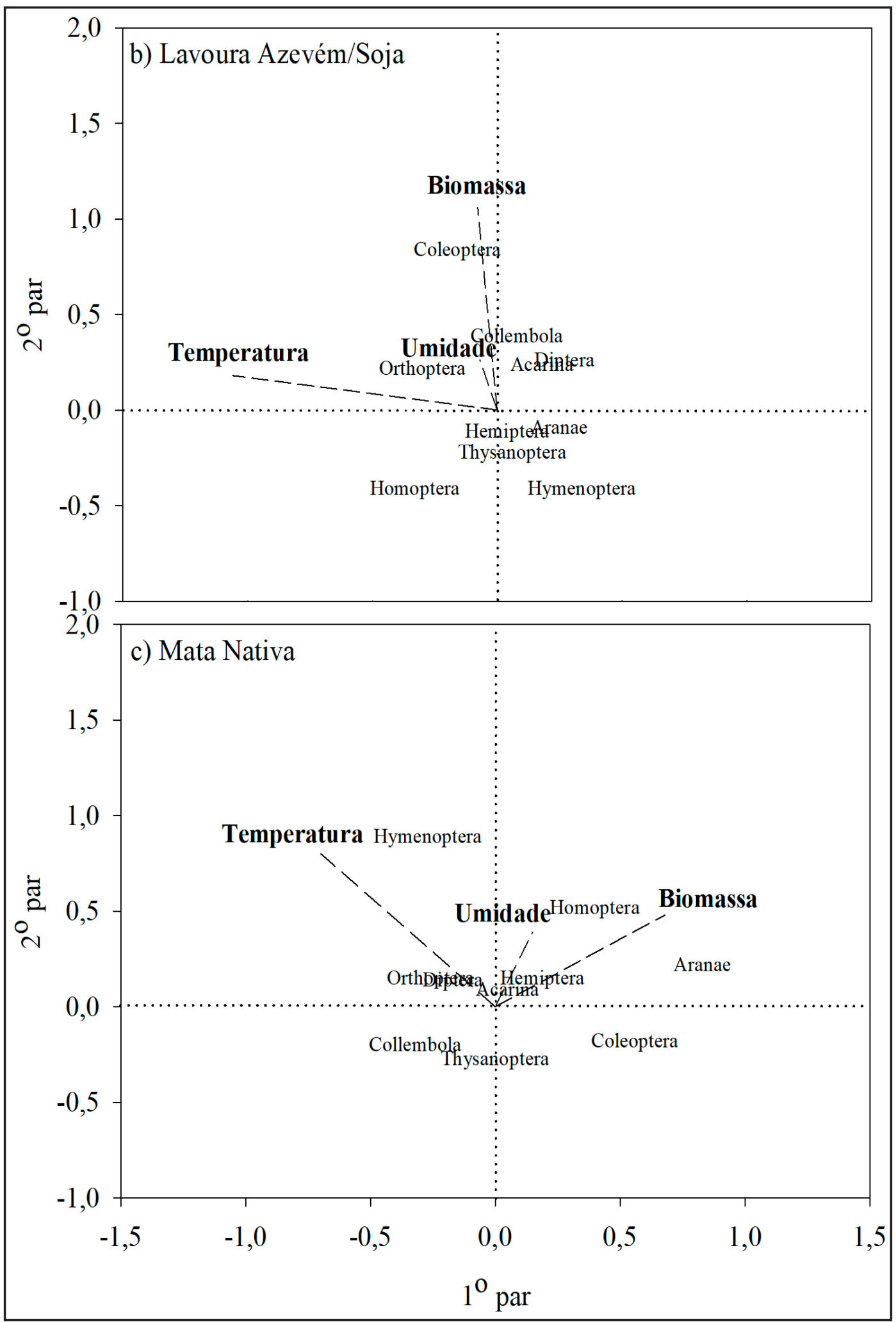

Fonte: Autores (2017) 


\section{CONCLUSÕES}

Há elevada abundância de organismos do solo nas áreas avaliadas no Bioma Pampa, sendo os grupos taxonômicos Collembola, Hymenoptera e Acarina os mais abundantes nas três áreas independentemente da época de coleta.

A Mata Nativa possui maior uniformidade e diversidade biológica do que outros usos do solo.

A área de Lavoura Azevém/Soja apresentou baixa uniformidade e diversidade biológica, indicando que usos do solo com monocultivos e baixa adição de biomassa vegetal são desfavoráveis à preservação da biodiversidade do solo.

O uso do solo com Campo Nativo Pastejado no Bioma Pampa mostra-se favorável à preservação da biodiversidade do solo e desse bioma.

Os diferentes grupos da fauna do solo respondem de maneiras distintas às variáveis ambientais, portanto estudos mais aprofundados do comportamento de cada grupo no solo, bem como sua reação aos fatores externos podem ter uma grande importância na avaliação da qualidade do solo.

A fauna edáfica mostra potencial para ser utilizada na avaliação da qualidade do solo, já que alguns grupos mostraram ser sensíveis às mudanças de variáveis ambientais.

\section{REFERÊNCIAS}

ANDERSON, J. M. Why should we care about soil fauna? Pesquisa Agropecuária Brasileira, Brasília, v. 44, p. 835-842, 2009.

ANTONIOLLI, Z. I. et al. Método alternativo para estudar a fauna do solo. Ciência Florestal, Santa Maria, v. 16, n. 4, p. 407-417, 2007.

AQUINO, A. M. et al. Invertebrate soil macrofauna under different ground cover plantes in the no-till system in the Cerrado. European Journal of Soil Biology, Paris, v. 44, p. 91-97, 2008.

BARETTA, D. et al. Efeito do cultivo do solo sobre a diversidade da fauna do solo no planalto sul catarinense. Revista de Ciências Agroveterinárias, Lages, v. 5, n. 2, p. 108-117, 2006.

BARETTA, D. Fauna do solo e outros atributos edáficos como indicadores da qualidade ambiental em áreas com Araucaria angustifolia no Estado de São Paulo. 2007. Tese (Doutorado em Agronomia) - Universidade de São Paulo, Escola Superior de Agricultura Luiz de Queiroz, Piracicaba, 2007. 
CARVALHO, P. C. F; BATELLO, C. Access to land, livestock production and ecosystem conservation in the Brazilian Campos biome: the natural grasslands dilemma. Livestock Science, Amsterdam, v. 120, p. 158-162, 2009.

CHAUVAT, M.; ZAITSEV, A. S.; WOLTERS, V. Successional changes of Collembola and soil microbiota during forest rotation. Oecologia, Berlin, v. 137, n. 2, p. 269-276, 2003.

COSSEAU, L. et al. Levantamento de invertebrados epiedáficos em ambiente contaminado por chumbo. Research, Society and Development, Vargem Grande Paulista, v. 9, n. 3, p. e189932738, 2020.

CREPALDI, R. A. et al. Formigas como bioindicadores da qualidade do solo em sistema integrado lavoura-pecuária. Ciência Rural, Santa Maria, v. 44, n. 5, p. 781-787, 2014.

DUCATTI, F. Fauna edáfica em fragmentos florestais e em áreas reflorestadas com espécies da Mata Atlântica. 2002. Dissertação (Mestrado em Recursos Florestais) - Universidade de São Paulo, Escola Superior de Agricultura Luiz de Queiroz, Piracicaba, 2002.

GONÇALVES, J. L. M. et al. Reflexos do cultivo mínimo e intensivo do solo em sua fertilidade e na nutrição das árvores. In: GONÇALVES, J. L. M.; BENEDETTI, V. (ed.). Nutrição e fertilização florestal. Piracicaba: IPEF, 2000. p. 1-57.

GONGALSKY, K. B. et al. Diversity of the Soil Biota in Burned Areas (Tver Oblast) of Southern Taiga Forests. Eurasian Soil Science, Moscow, v. 49, p. 358-366, 2016.

JACCARD, P. Nouvelles recherches sur la distribution florale. Bulletin de la Socieété Vaudoise des Sciences Naturelles, [s. I.], v. 44, p. 223-270, 1908.

JEREZ-VALLE, C. et al. A simple bioindication method to discriminate olive orchard management types suing the soil arthropod fauna. Applied Soil Ecology, Pretty, v. 76, p. 42-51, 2014.

KLADIVKO, E. J. Tillage Systems and soil ecology. Soil \& Tillage Research, Amsterdam, v. 61, p. 61-76, 2001.

LAVELLE, P. et al. Soil invertebrates and ecosystem services. European Journal of Soil Biology, Jersey, v. 42, n. 1, p. 3-15, 2006.

LIMA, H. V. et al. Indicadores de qualidade do solo em sistemas de cultivo orgânico e convencional no semi-árido cearense. Revista Brasileira de Ciência do Solo, Viçosa, MG, v. 31, p. 1085-1098, 2007.

MAAß, S.; CARUSO, T.; RILLIG, M.C. Functional role of microarthropods in soil aggregation. Pedobiologia, Wageningen, v. 58, p. 59-63, 2015.

MELO, F. V. et al. A importância da meso e macrofauna do solo na fertilidade e como biondicadores. Boletim Informativo da SBCS, p. 38-42, jan./abr. 2009.

MORENTE, M., CAMPOS, M.; RUANO, F. Evaluation of two different methods to measure the effects of the management regime on the olive-canopy arthropod community. Agriculture, Ecosystems and Environment, Amsterdam, v. 259, p. 111-118, 2018. 
PASQUALIN, L. P. et al. Macrofauna edáfica em lavouras de cana-de-açúcar e mata do noroeste do Paraná - Brasil. Semina, Londrina, v. 33, p. 7-18, 2012.

PESSOA, M. L. (org.). Clima do RS. In: PESSOA, M. L. (org.). Atlas FEE. Porto Alegre: FEE, 2017. Disponível em: http://atlas.fee.tche.br/rio-grande-do-sul/socioambiental/clima/. Acesso em: 31 jul. 2020.

REICHERT, J. M.; REINERT, D. J.; BRAIDA, J. A. Qualidade do solo e sustentabilidade de sistemas agrícolas. Ciência \&Ambiente, Santa Maria, v. 27, n. 1, p. 29-48, 2003.

ROESCH, L. F. W. et al. The Brazilian Pampa: a fragile biome. Diversity, Basel, v. 1, p. 182-198, 2009.

SANGINGA, N.; MULONGOY, K.; SWIFT, M. J. Contribution of soil organisms to the sustainability and productivity cropping systems in the tropics. Agriculture, Ecosystems \& Environment, Amsterdam, v. 41, n. 2, p. 135-152, 1992.

SAS INSTITUTE. Enterprises Guide. Version 4.2. Cary, 2008.

SILVA, D. A. A. et al. Bioindicadores de qualidade edáfica em diferentes usos do solo. Enciclopédia Biosfera, Goiânia, v. 11 n. 22, p. 3728-3736, 2015.

SILVA, R. F. et al. Macrofauna invertebrada do solo sob diferentes sistemas de produção em Latossolo da região do cerrado. Pesquisa Agropecuária Brasileira, Brasília, v. 41, p. 697-704, 2006.

SOUTO, P. C. et al. Comunidade microbiana e mesofauna edáfica em solo sob Caatinga no semiárido da Paraíba. Revista Brasileira de Ciência do Solo, Viçosa, MG, v. 32, n. 1, p. 151$160,2008$.

VILARDO, G. et al. Soil arthropod composition differs between old-fields dominated by exotic plant species and remnant native grasslands. Acta Oecologica, Paris, v. 91, p. 57-64, 2018.

\section{Contribuição de Autoria}

\section{1 - Querina Ramos de Góes}

Gestora Ambiental, Pesquisadora Autônoma

https://orcid.org/0000-0003-2068-2961•querinagoes@gmail.com

Contribuição: Administração do projeto, Investigação, Análise Formal, Curadoria de dados, Escrita - primeira redação 


\section{2 - Letiéri da Rosa Freitas}

Engenheira Florestal, Pesquisadora Autônoma

https://orcid.org/0000-0002-6421-4329•letierifreitas@gmail.com

Contribuição: Investigação, Análise Formal, Curadoria de dados

\section{3 - Leandro Homrich Lorentz}

Engenheiro Agrônomo, Dr., Professor

https://orcid.org/0000-0003-2953-5167•leandrolorentz@unipampa.edu.br

Contribuição: Administração do projeto, Análise Formal, Curadoria de dados, Escrita primeira redação

\section{4 - Frederico Costa Beber Vieira}

Engenheiro Agrônomo, Dr., Professor

https://orcid.org/0000-0001-5565-7593•fredericovieira@unipampa.edu.br

Contribuição: Administração do projeto, Análise Formal, Curadoria de dados, Escrita primeira redação

\section{5 - Mirla Andrade Weber}

Engenheira Agrônoma, Dra., Professora

https://orcid.org/0000-0001-9684-8919•mirlaweber@unipampa.edu.br

Contribuição: Administração do projeto, Investigação, Supervisão, Análise Formal, Curadoria de dados, Escrita - primeira redação

\section{Como citar este artigo}

Góes, Q. R.; Freitas, L. R.; Lorentz, L. H.; Vieira, F. C. B.; Weber, M. A. Análise da fauna edáfica em diferentes usos do solo no Bioma Pampa. Ciência Florestal, Santa Maria, v. 31, n. 1, p. 123-144, 2021. DOI 10.5902/1980509832130. Disponível em: https://doi.org/10.5902/1980509832130. Acesso em: xx mês abreviado 202x. 